\title{
'Pneumonia Weather': Short-term Effects of Meteorological Factors on Emergency Room Visits Due to Pneumonia in Seoul, Korea
}

\author{
Sangho Sohn', Wonju Cho², Jin A Kim², Alaa Altaluoni², Kwan Hong' ${ }^{1}$, Byung Chul Chun ${ }^{1}$ \\ ${ }^{1}$ Department of Preventive Medicine, Korea University College of Medicine, Seoul, Korea, ${ }^{2}$ Korea University Graduate School of Public Health, Seoul, \\ Korea
}

Objectives: Many studies have explored the relationship between short-term weather and its health effects (including pneumonia) based on mortality, although both morbidity and mortality pose a substantial burden. In this study, the authors aimed to describe the influence of meteorological factors on the number of emergency room (ER) visits due to pneumonia in Seoul, Korea.

Methods: Daily records of ER visits for pneumonia over a 6-year period (2009-2014) were collected from the National Emergency Department Information System. Corresponding meteorological data were obtained from the National Climate Data Service System. A generalized additive model was used to analyze the effects. The percent change in the relative risk of certain meteorological variables, including pneumonia temperature (defined as the change in average temperature from one day to the next), were estimated for specific age groups.

Results: A total of $217776 \mathrm{ER}$ visits for pneumonia were identified. The additional risk associated with a $1^{\circ} \mathrm{C}$ increase in pneumonia temperature above the threshold of $6^{\circ} \mathrm{C}$ was 1.89 (95\% confidence interval [Cl], 1.37 to 2.61). Average temperature and diurnal temperature range, representing within-day temperature variance, showed protective effects of $0.07(95 \% \mathrm{Cl}, 0.92$ to 0.93$)$ and 0.04 (95\% $\mathrm{Cl}, 0.94$ to 0.98$)$, respectively. However, in the elderly (65+ years), the effect of pneumonia temperature was inconclusive, and the directionality of the effects of average temperature and diurnal temperature range differed.

Conclusions: The term 'pneumonia temperature' is valid. Pneumonia temperature was associated with an increased risk of ER visits for pneumonia, while warm average temperatures and large diurnal temperature ranges showed protective effects.

Key words: Pneumonia, Weather, Emergency service, Generalized additive model, Public health

Received: October 4, 2018 Accepted: December 31, 2018

Corresponding author: Byung Chul Chun, MD, PhD Department of Preventive Medicine, Korea University College of Medicine, 73 Inchon-ro, Seoungbuk-gu, Seoul 02841, Korea E-mail: chun@korea.ac.kr

This is an Open Access article distributed under the terms of the Creative Commons Attribution Non-Commercial License (http://creativecommons.org/licenses/by$\mathrm{nc} / 4.0 /$ ) which permits unrestricted non-commercial use, distribution, and reproduction in any medium, provided the original work is properly cited.

\section{INTRODUCTION}

In recent mortality statistics, pneumonia has risen to become the fourth most common cause of death in Korea, following cancer, cardiovascular disease, and cerebrovascular disease [1]. Despite the incorporation of pneumococcal vaccines into the national immunization program, a significant number of patients, especially younger children and elderly patients, suffer from pneumonia. 
Different studies have explored the possible effects of various meteorological factors on pneumonia and other respiratory diseases. Temperature is a well-known factor, and is likely the least disputable contributor [2-6]. Some studies have reported J-shaped, U-shaped, or V-shaped relationships of temperature with pneumonia, but the patterns seem to vary by study location [2-4] and temperature range (i.e., between colder or warmer temperatures) $[5,6]$. The diurnal temperature range (DTR), representing the temperature variance within a day, has also been observed to influence general health [7] and respiratory conditions $[8,9]$. Correlations between precipitation or relative humidity $(\mathrm{RH})$ and pneumonia have been reported in countries with abundant rainfall [10-12].

The public also has empirical notions about the health effects of weather. In Western countries, people are aware of socalled 'pneumonia weather' - that is, when it suddenly becomes warmer during the cold season, people perceive themselves to be at risk for developing pneumonia. In Korea, weather forecasts alert the public to take steps to prevent catching a cold when the DTR is expected to be high.

Efforts to elucidate relationships between meteorological factors and health conditions have so far focused on specific weather variables in relatively broad areas, with mortality data as an endpoint [13]. However, since the weather is a multifaceted phenomenon to which various meteorological factors contribute, it can be difficult to disentangle specific effects from others. Furthermore, morbidity is another important outcome of public health issues. Therefore, this study focused on investigating the relationship between the number of pneumonia cases presenting to emergency rooms (ERs) and meteorological factors in Seoul, Korea. We also sought to clarify the reasonability of the empirical term 'pneumonia weather' and estimated its short-term impact through a time-series analysis.

\section{METHODS}

The case counts of pneumonia patients who visited ERs in Seoul between January 1, 2009 and December 31, 2014, were the focus of this study. ERs in Korea are stratified into 4 classes: the National Emergency Medical Center, which governs all other institutions, local emergency medical centers (EMCs), regional EMCs, and regional emergency medical service institutions. Among these institutions, most major hospitals participate in the National Emergency Department Information System (NEDIS). Therefore, when a patient visits an ER, relevant data such as time, age, and diagnosis are recorded and incorporated into the system in real time. Cases were defined based on the International Classification of Diseases, 10th Revision. We extracted records from the NEDIS database for cases where the diagnosis at the time of ER discharge included any type of pneumonia (J12-J18). For the first 5 years of our study period, there were 30 ERs in Seoul within the NEDIS. Another institution was added in 2014, but data from that institution were excluded for consistency of the analysis.

The Korea Meteorological Administration provides open access to its weather database. We collected daily observations on average, minimum, and maximum temperatures; $\mathrm{RH}$; precipitation; and wind speed (WS) for our study period from the Seoul observatory. From this data, we generated two additional variables: the DTR defined as the difference between the minimum temperature and maximum temperature on a given day, and pneumonia temperature, defined as the current day's average temperature minus the previous day's average temperature. $\mathrm{A}$ higher pneumonia temperature indicates that a given day was warmer than the previous day, and vice versa.

Time-series plots for pneumonia ER visits and weather variables were reviewed and investigated for any trends other than seasonality. Spearman correlation coefficients were cal-

Table 1. Number of daily emergency room visits for pneumonia in Seoul from 2009 to 2014

\begin{tabular}{lc}
\hline Variables & Cases, $\mathbf{n}(\%)$ \\
\hline Year & \\
2009 & $33913(24.8)$ \\
2010 & $31276(14.4)$ \\
2011 & $34742(15.9)$ \\
2012 & $32819(15.1)$ \\
2013 & $24941(11.4)$ \\
2014 & $40085(18.4)$ \\
Sex & \\
Male & $119354(54.8)$ \\
Female & $98422(45.2)$ \\
Age (y) & \\
$0-5$ & $84383(38.7)$ \\
$6-18$ & $28860(13.2)$ \\
$19-64$ & $54926(25.2)$ \\
$\geq 65$ & $49607(22.8)$ \\
Holidays & \\
Non-holiday & $165511(76.0)$ \\
Holiday & $52265(24.0)$ \\
Sunday & $41544(19.1)$ \\
\hline & \\
\hline
\end{tabular}


culated between the meteorological factors to avoid collinearity. In Seoul, most precipitation occurs during the rainy season in summer. For this reason, we decided to discard the precipi- tation data and instead apply RH, which has valid and computable daily data throughout the study period. Since the assumption of linearity rarely holds for meteorological effects on
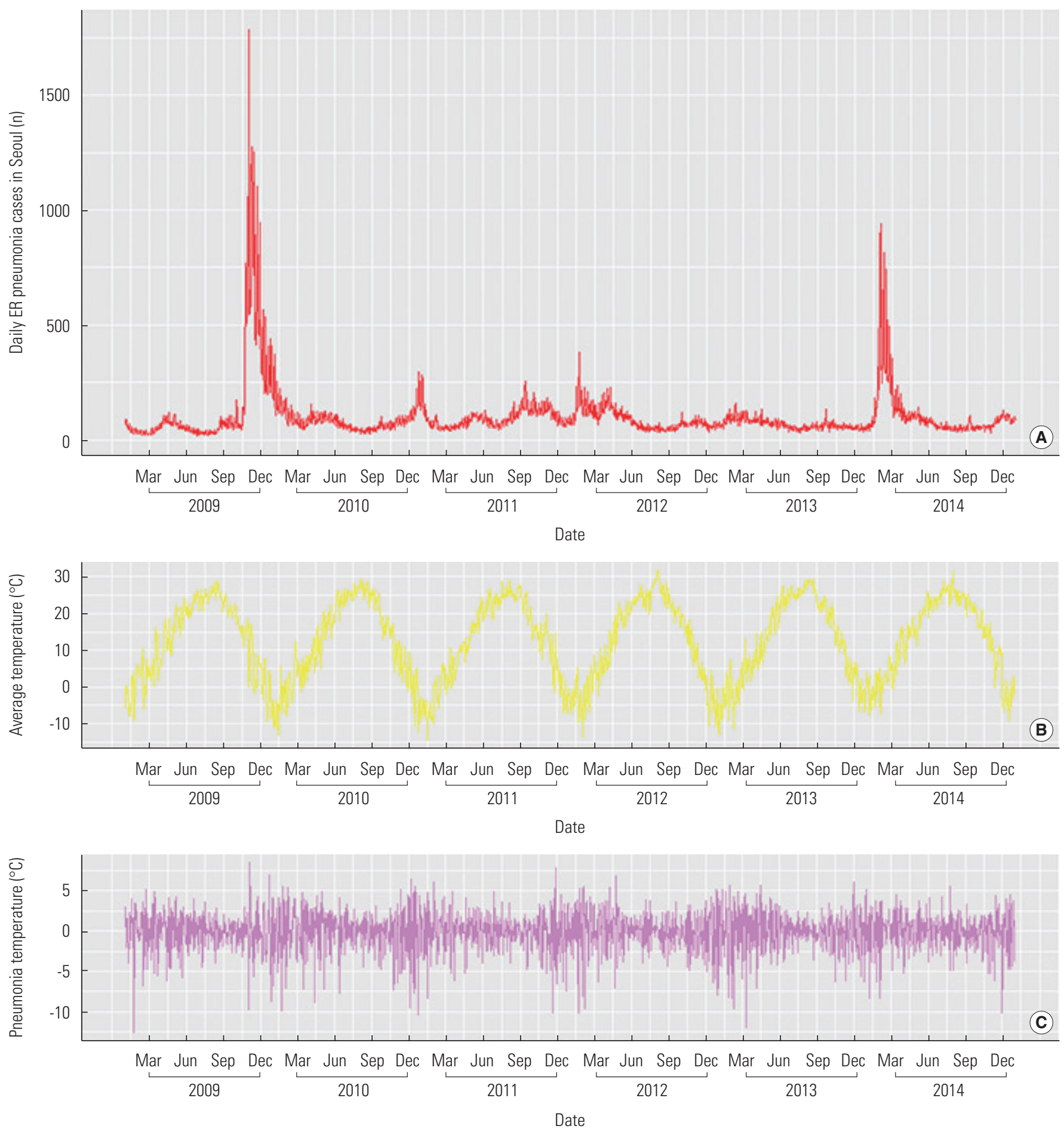

Figure 1. Time-series plots of pneumonia ER cases (A) and meteorological variables (B: average temperature, C: pneumonia temperature, D: DTR, E: precipitation, F: relative humidity). No changes in the overall trend were found for either the case count of pneumonia patients visiting the ER or for each meteorological factor. However, the number of patients peaked in 2009 due to pandemic influenza. ER, emergency room; DTR, diurnal temperature range.

(Continued to the next page) 


\section{Journal of}

ER visits, we applied a generalized additive model (GAM) using a log link function. A negative binomial distribution was assumed to handle the overdispersion issue. We included time as an ordinal number of calendar days on day $t$, and Holiday as a dummy variable for Sundays or public holidays to adjust for their potential confounding effects. For the number of knots and degrees of freedom of the models, we adapted the values estimated by the mgcv package using default settings. The
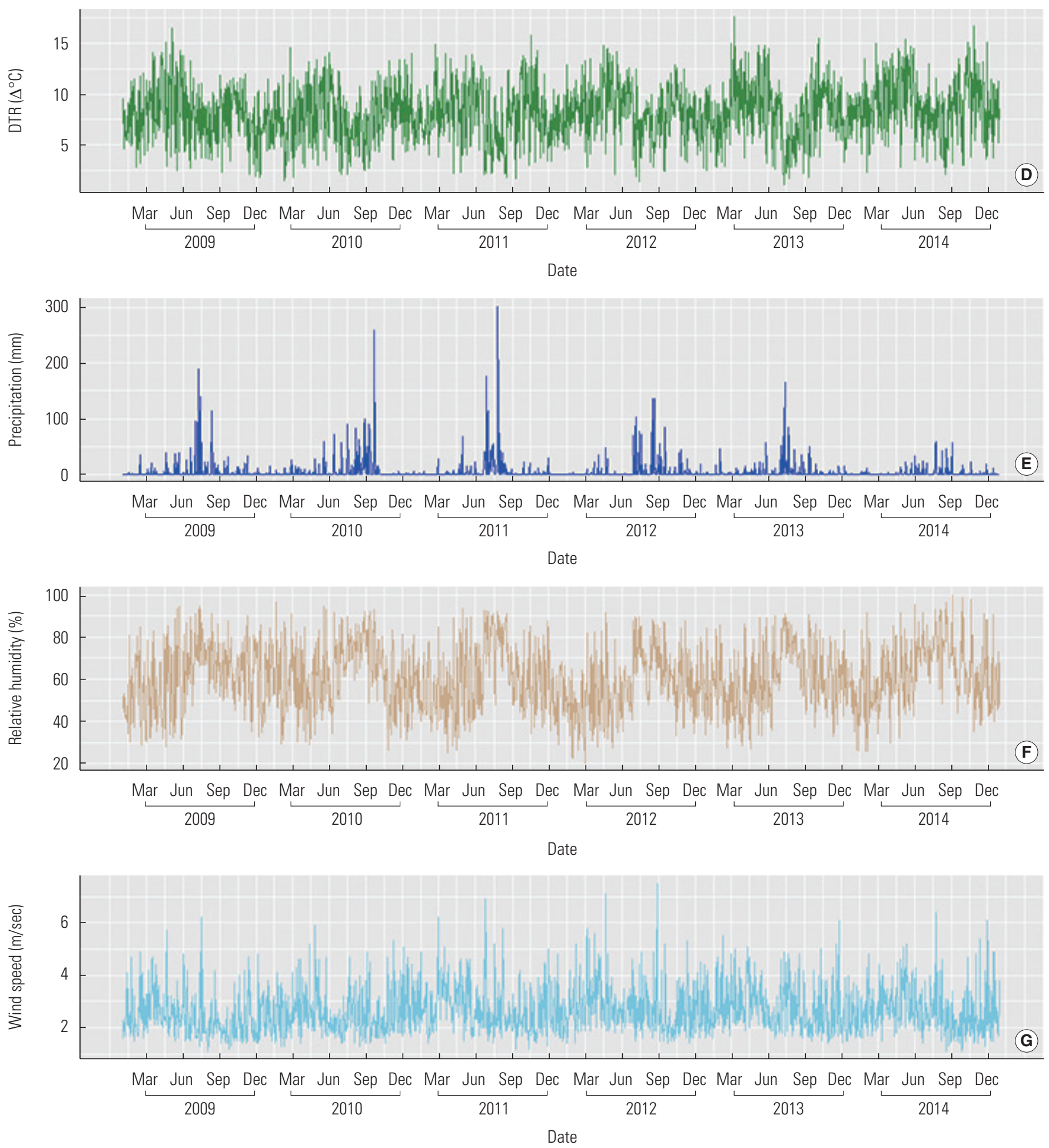

Figure 1. Continued from the previous page. 
base model equation was as follows:

$\log \left(\mathrm{E}\left[\mathrm{Y}_{\mathrm{t}}\right]\right)=\beta_{0}+\mathrm{s}\left(T_{\mathrm{PN}}, \mathrm{df}\right)+\mathrm{s}\left(T_{\mathrm{AVE}}, \mathrm{df}\right)+\mathrm{s}(D T R, \mathrm{df})+\mathrm{s}(R H, \mathrm{df})+\mathrm{s}(W S, \mathrm{df})+\cos ($ time $)+$ Holiday,

where $E\left(Y_{t}\right)$ refers to the expected count of pneumonia cases presenting to the ER, $s()$ is the spline function smoothing non-linear variables, $T_{\mathrm{PN}}$ refers to the pneumonia temperature, $T_{\mathrm{AVE}}$ is the average temperature, DTR is the diurnal temperature range, $R H$ is the relative humidity, and $W S$ is wind speed.

Pneumonia often results from the subacute progression of previously acquired upper respiratory infections. Thus, it is reasonable to simultaneously evaluate the delayed effect of certain meteorological conditions on triggering pneumonia. For this reason, along with the current day's effect, which is denoted by lago, we also applied single lags from $\operatorname{lag}_{1}$ to $\operatorname{lag}_{7}$ and cumulative lags from $\operatorname{lag}_{0-1}$ to $\operatorname{lag}_{0-7}$ for the average temperature and DTR. However, only single lags were used for pneumonia temperature because the purpose of this parameter was to evaluate the risk, if any, posed by a sudden increase or drop of temperature between 2 consecutive days. Cumulative lags, which contain an average of 2 days or more, did not suit this purpose. Second, the temperature difference between consecutive days in actual ambient conditions is usually small or gradual, rather than fluctuating, so that the accumulation of more lags would cause the average to converge to zero. Accordingly, we built and tested various lag models using every possible combination with 7 single lags or 14 single and cumulative lags for each variable, and chose the best lag model based on the Akaike information criterion.

Spline curves of meteorological variables were plotted using the best lag model. For linearly increasing or decreasing curves, the relative risk (RR) for each unit change was estimated. If the curve appeared to have any inflection point, such as a V-shape or plateau, a breakpoint based on the r-square was determined and piecewise regression was done to estimate the RR for each segment. The process was then repeated with subgroup data by age, especially focusing on younger children and the elderly, who were most likely to be affected by pneumonia. Computations were carried out using SAS version 9.4 (SAS Institute Inc., Cary, NC, USA) for data handling and R-studio version 1.0.153 with the $m g c v$ package for the GAM analysis.

The Korea University Institutional Review Board reviewed the study design and approved a waiver (KU-IRB-17-EX-257-A-1).

\section{RESULTS}

During the 6 years of the study period, 217776 ER visits for pneumonia were recorded (Table 1). The number of cases peaked in 2009 owing to the pandemic of influenza A. The age group distribution showed apparent vulnerability in younger children ( 5 years or younger) and in the elderly (aged 65 years or older), while adolescents seemed less likely to be affected. The timeseries plots for total cases and meteorological variables are provided in Figure 1. No overall trend other than seasonality was observed.

Table 2 summarizes the investigated meteorological factors, showing the temperate climate characteristics of Seoul. The wide range in average temperatures indicates that Seoul experiences hot summers and cold winters. Precipitation is extremely right-skewed, because the rainy season is in the summer, whereas $\mathrm{RH}$ is fairly evenly distributed. $\mathrm{RH}$ and precipitation were moderately correlated (data not shown).

The spline curves generated by the GAM analysis, as shown in Figure 2, demonstrated the patterns of the relationships between each meteorological variable and ER visits for pneumonia from the best lag models for (A) all age groups, (B) younger children, and (C) the elderly.

The pneumonia temperature for all age groups (Figure 2A) showed an $\mathrm{N}$-shaped pattern with a relatively flat segment in the middle. For example, when the pneumonia temperature was $6^{\circ} \mathrm{C}$ or higher (i.e., when it suddenly became warmer than the previous day), an increased risk of pneumonia could be expected after 7 days. On the contrary, when the pneumonia temperature was $-10^{\circ} \mathrm{C}$ or lower (i.e. when it suddenly became colder than the previous day) the risk of pneumonia after 7 days was decreased. A 7-day average temperature of $14^{\circ} \mathrm{C}$ or higher showed a protective effect, whereas no noticeable risk changes were found for the DTR, RH, or WS.

Table 2. Summary statistics of meteorological factors in Seoul

\begin{tabular}{lrrrrrrr}
\hline Factors & Mean & SD & Min & Q1 & $\mathbf{0 2}$ & $\mathbf{0 3}$ & Max \\
\hline $\mathrm{T}_{\text {AVE }}\left({ }^{\circ} \mathrm{C}\right)$ & 12.6 & 10.9 & -14.5 & 3.4 & 14.2 & 22.7 & 31.8 \\
$\mathrm{DTR}\left({ }^{\circ} \mathrm{C}\right)$ & 8.2 & 2.8 & 1.1 & 6.2 & 8.2 & 10.2 & 17.6 \\
$\mathrm{RH}(\%)$ & 60.5 & 15.1 & 20.1 & 49.4 & 60.4 & 71.6 & 99.8 \\
$\mathrm{PR}(\mathrm{mm} / \mathrm{d})$ & 4.3 & 17.2 & 0.0 & 0.0 & 0.0 & 0.5 & 301.5 \\
$\mathrm{WS}(\mathrm{m} / \mathrm{sec})$ & 2.6 & 0.9 & 1.1 & 2.0 & 2.5 & 3.1 & 7.5 \\
\hline
\end{tabular}

SD, standard deviation; Min, minimum; Max, maximum; $T_{\text {AVE, }}$ daily average temperature; DTR, diurnal temperature range; $\mathrm{RH}$, relative humidity; PR, daily precipitation; WS, daily average wind speed. 

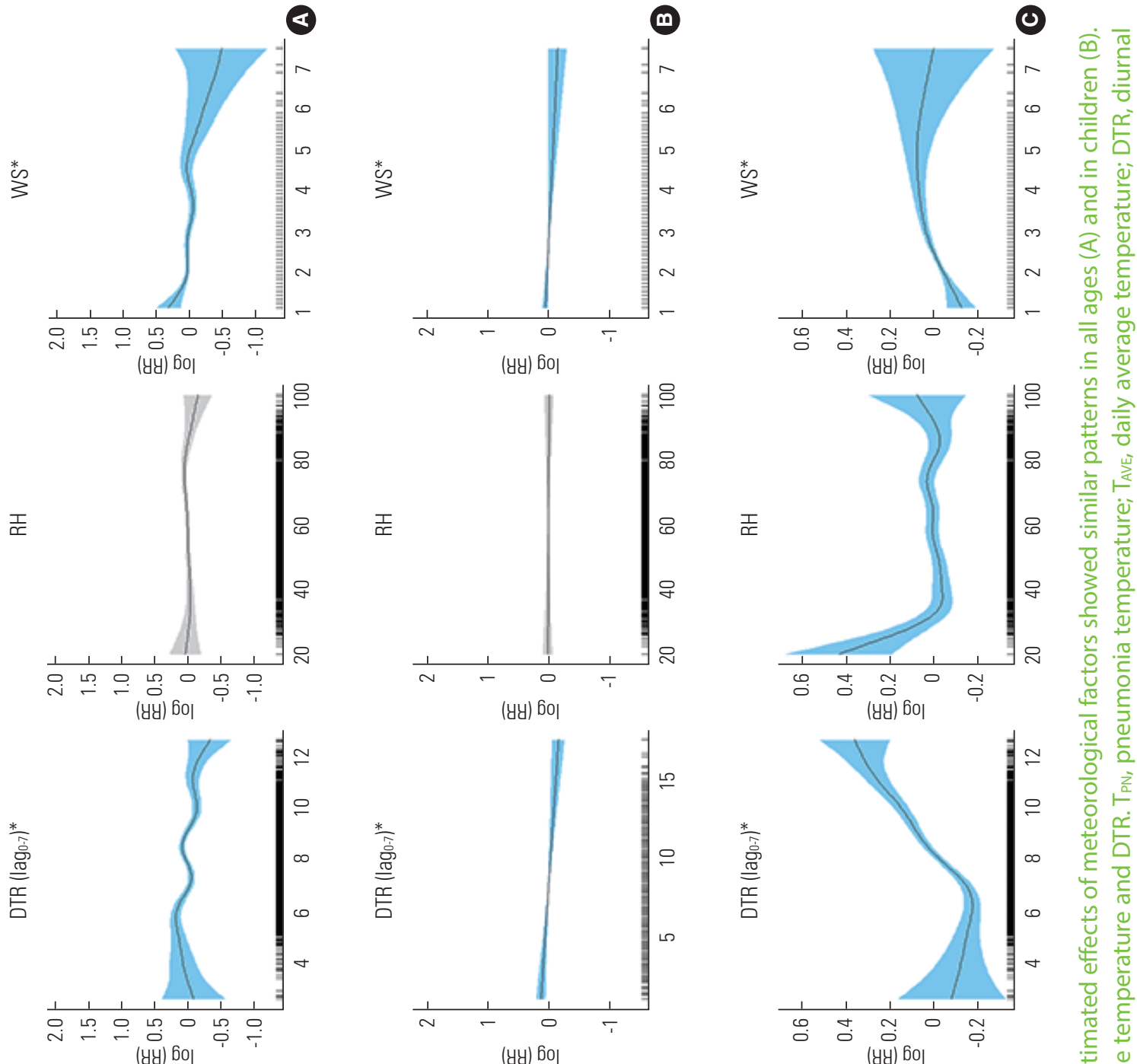

$\stackrel{I}{\Phi}$

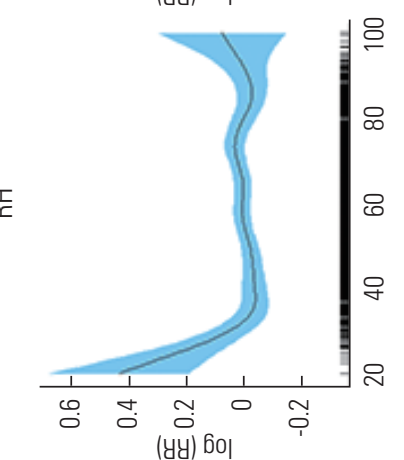

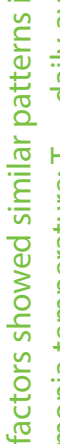
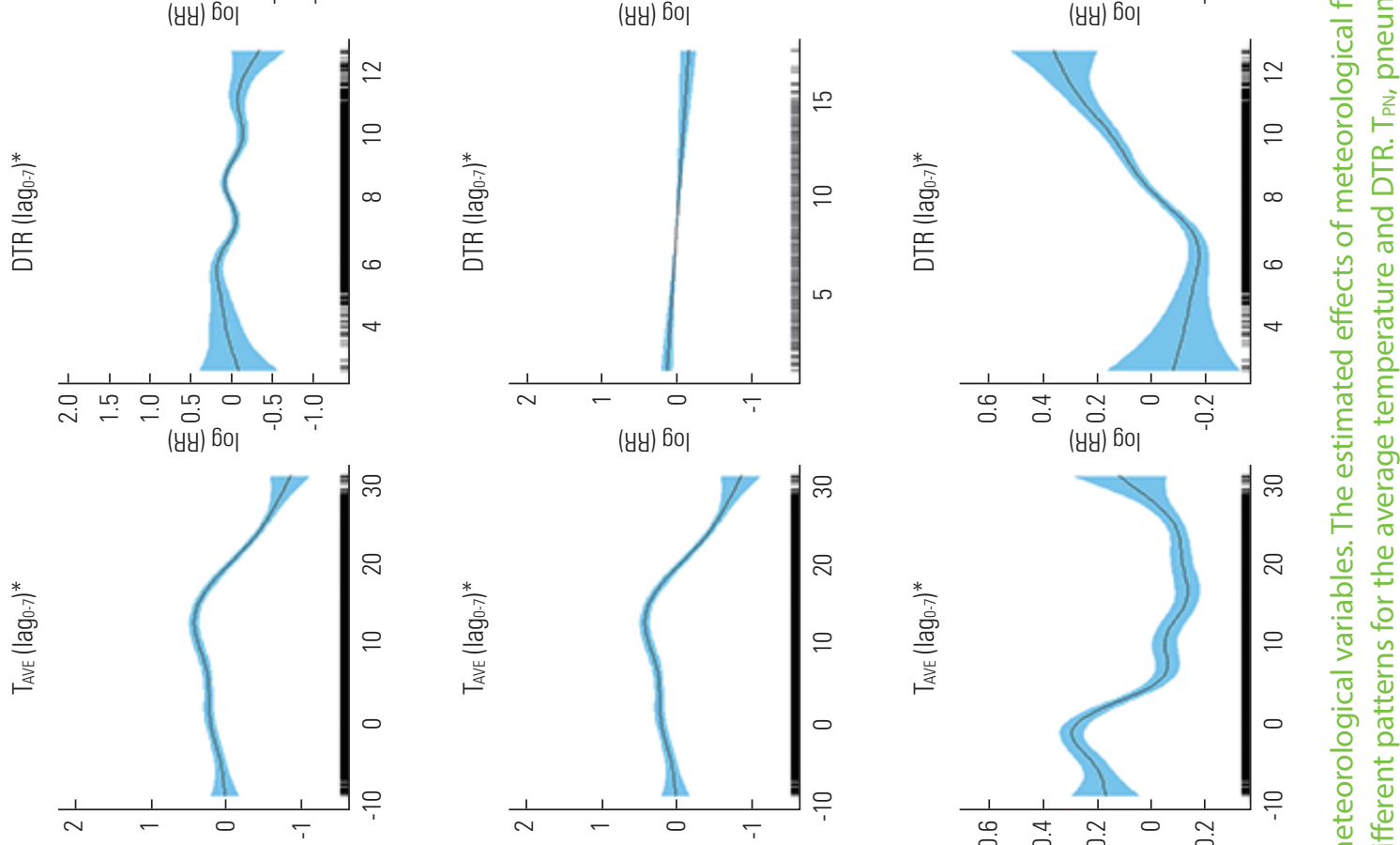

(ууу) 60
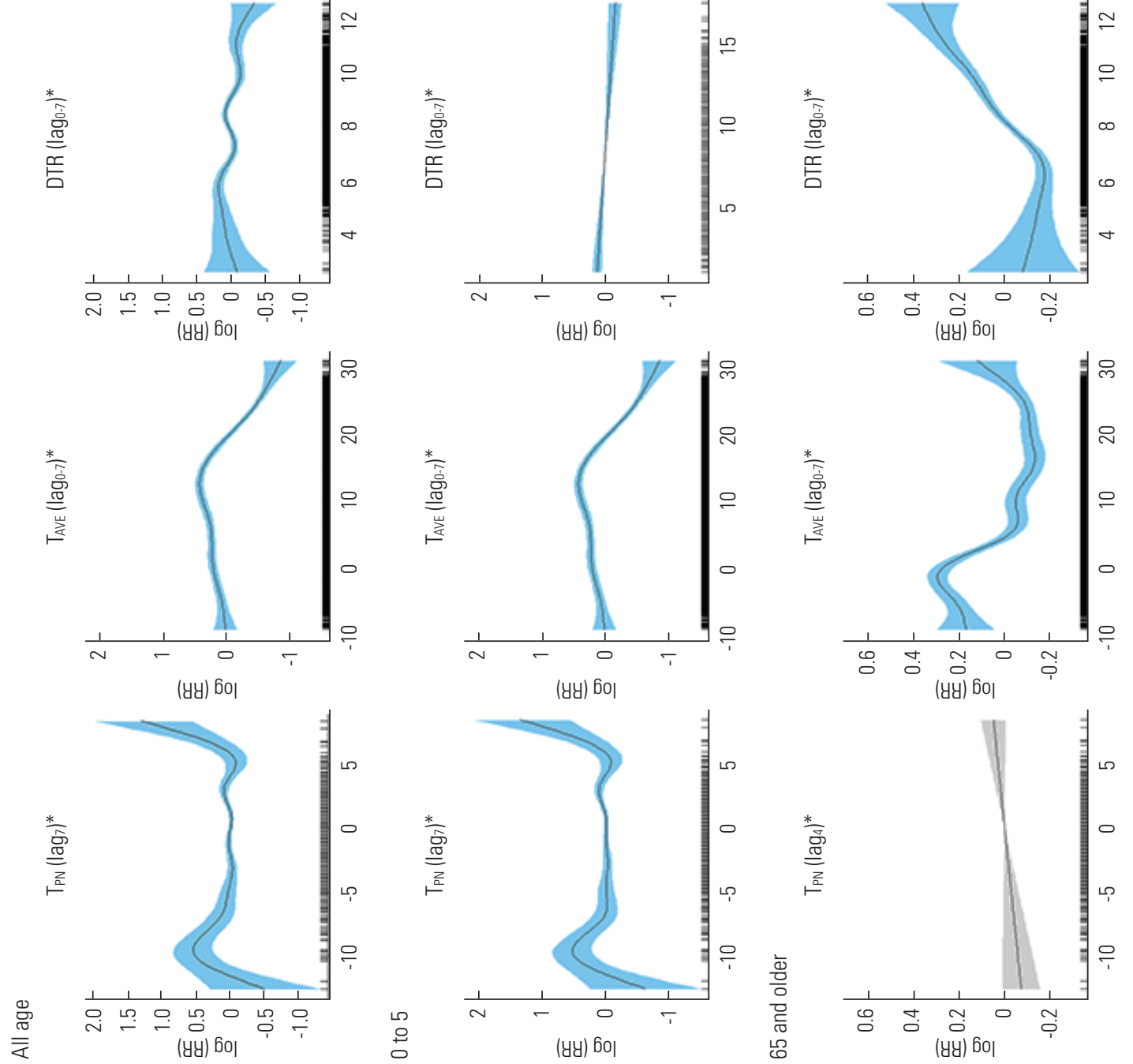

등ํㅇ

읜

造

틈ำ

施

苋高

致 듐

ث

은

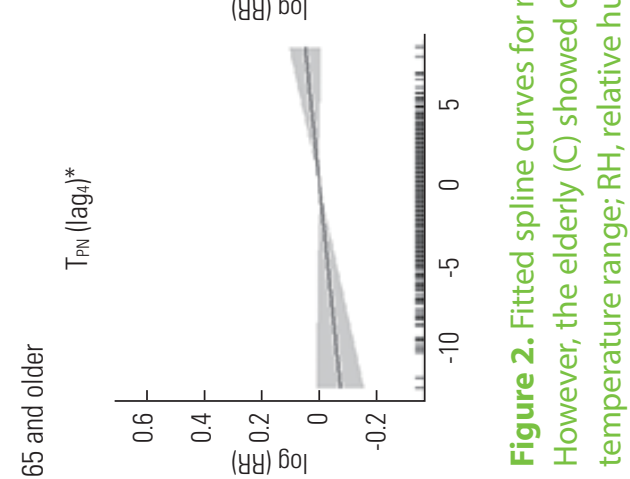


Table 3. Effects of meteorological factors on emergency room visits for pneumonia

\begin{tabular}{|c|c|c|c|c|c|c|}
\hline \multirow{2}{*}{ Age (y) } & \multicolumn{3}{|c|}{$\mathrm{T}_{\mathrm{PN}}$} & \multicolumn{2}{|c|}{$\mathrm{T}_{\mathrm{AVE}}$} & \multirow{2}{*}{$\begin{array}{c}\text { DTR } \\
\text { RR }(95 \% \mathrm{CI})\end{array}$} \\
\hline & \multicolumn{3}{|c|}{ Segment RR (95\% CI) } & \multicolumn{2}{|c|}{ Segment RR $(95 \% \mathrm{CI})$} & \\
\hline \multirow[t]{2}{*}{$\overline{A l l}{ }^{1}$} & $T_{\text {PN }}<-10$ & $-10 \leq T_{\mathrm{PN}}<6$ & $6 \leq \mathrm{T}_{\mathrm{PN}}$ & $\mathrm{T}_{\mathrm{AVE}}<14$ & $14 \leq \mathrm{T}_{\text {AVE }}$ & - \\
\hline & $1.40(1.00,1.98)$ & $0.99(0.98,1.00)$ & $1.89(1.36,2.61)^{*}$ & $1.01(1.01,1.02)^{*}$ & $0.93(0.92,0.93)^{*}$ & $0.96(0.94,0.98)^{*}$ \\
\hline \multirow[t]{2}{*}{$0-5^{2}$} & $\mathrm{~T}_{\mathrm{PN}}<-10$ & $-10 \leq T_{P N}<6$ & $6 \leq T_{P N}$ & $\mathrm{~T}_{\text {AVE }}<14$ & $14 \leq \mathrm{T}_{\text {AVE }}$ & - \\
\hline & $1.45(0.99,2.11)$ & $1.00(0.99,1.01)$ & $1.89(1.34,2.67)^{*}$ & $1.02(1.01,1.03)^{*}$ & $0.92(0.91,0.92)^{*}$ & $0.98(0.97,0.99)^{*}$ \\
\hline \multirow[t]{2}{*}{$>65^{3}$} & & Not measured & & $\mathrm{T}_{\mathrm{AVE}}<16$ & $16 \leq \mathrm{T}_{\mathrm{AVE}}$ & - \\
\hline & & & & $0.98(0.98,0.98)^{*}$ & $1.01(1.00,1.02)^{*}$ & $1.08(1.06,1.09)^{*}$ \\
\hline
\end{tabular}

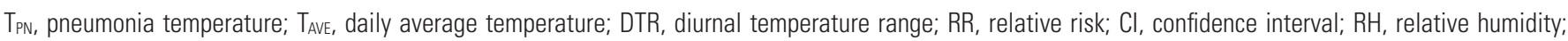
WS, daily average wind speed.

${ }^{1}$ Controlled for $T_{\text {PN }}$ lag $_{7}, T_{\text {AvE }}$ lag $_{0-7}$, DTR lag $0-7$, RH, WS, holiday, time.

${ }^{2}$ Controlled for $T_{\text {PN }}$ lag $_{7}, T_{\text {AvE }}$ lag $_{0-7}$, DTR lag,, RH, WS, holiday, time.

${ }^{3}$ Controlled for $T_{\text {PN }} \operatorname{lag}_{4}, T_{\text {AVE }} \operatorname{lag}_{0-7}$, DTR lag $0-7$, RH, WS, holiday, time.

${ }^{*} p<0.05$.

In children, the best model for the DTR was single lag7, while the other factors had similar patterns to those in all age groups (Figure 2B). However, the elderly showed different relationships (Figure 2C). The best lag for the pneumonia temperature was single $\operatorname{lag}_{4}$, and the trend was linear (near null), without significance. The best lags were the same for average temperature and DTR, but with an opposite pattern. Risk increased on both sides of the breakpoint as the average temperature fell below or rose above $16^{\circ} \mathrm{C}$, and an elevated DTR was associated with increased risk after 7 cumulative days.

Based on the fitted meteorological curves, the pneumonia temperature in all ages and children, and average temperature in all ages, children, and the elderly appeared to have breakpoints with different RRs for each interval. Table 3 shows the RRs that were estimated using segmented regression. When the pneumonia temperature was higher than $6^{\circ} \mathrm{C}$, each additional $1{ }^{\circ} \mathrm{C}$ increase resulted in an 1.89 (95\% confidence interval [Cl], 1.36 to 2.61$)$ to $1.89(95 \% \mathrm{Cl}, 1.34$ to 2.67$)$ increase in the RR for an ER visit due to pneumonia. The breakpoint for average temperature was $14^{\circ} \mathrm{C}$ in all ages and in children. Each degree warmer above this point was shown to present a 0.07 ( $95 \% \mathrm{Cl}, 0.92$ to 0.93$)$ or $0.08(95 \% \mathrm{Cl}, 0.91$ to 0.92$)$ change in the $\mathrm{RR}$, respectively. However, in the elderly, the reverse effect was observed with a breakpoint of $16^{\circ} \mathrm{C}$, and the size of the effect was also small ( 0.02 change; $95 \% \mathrm{Cl}, 0.98$ to 0.98 ). The RR for pneumonia temperature was not measured because the fitted spline curve did not show significance.

The DTR showed a linear relationship in every age group, but with different directions. In all ages and in children, increasing DTR served as a protective factor, and the magnitude of the effect was slightly higher in all ages than in children, with $0.04(95 \% \mathrm{Cl}, 0.94$ to 0.98$)$ and $0.02(95 \% \mathrm{Cl}, 0.97$ to 0.99$)$ reductions in the RR, respectively. In contrast, each unit increase in the DTR was related to an $0.08(95 \% \mathrm{Cl}, 1.06$ to 1.09) increase in the RR for ER visits due to pneumonia among the elderly.

\section{DISCUSSION}

Korea is known to have a temperate climate, although more extreme weather conditions such as heat waves or cold snaps have been observed in recent years. Consequently, understanding the health effects of climate change is emerging as a significant issue [14]. Our study demonstrated that the average temperature and DTR were related to the risk of pneumonia, although the magnitude and direction of the relationship varied across age groups. We also revealed that 'pneumonia weather' is not merely a casual expression, but is actually a valid term. To the best of our knowledge, this is the first study to investigate associations between NEDIS data and meteorological variables to identify the acute and subacute impacts of weather on specific health outcomes in Korea.

No consensus exists regarding the definition of 'pneumonia weather' or the pneumonia temperature, so we investigated abrupt temperature changes in both directions (colder to warmer and warmer to colder), and found that the former (i.e., a higher pneumonia temperature) increased the risk of pneumonia, especially in children. The risk was best explained when a 7-day lag was considered, which is reasonable considering the clinical course of pneumonia [15]. This finding can also be contextualized within people's health behavior during the cold season: when it suddenly becomes warmer in the winter, peo- 
ple start to dress lightly. However, since the warmer weather does not last long, they are exposed to infections that eventually lead to pneumonia. Since people feel weather changes more sharply when it occurs in the opposite direction (e.g. warm to cold, rather than warm to warmer), we propose that the effect of higher pneumonia temperatures can be interpreted as a combination of an association with the cold season and less tolerance to this pattern of temperature change. Previous studies have identified the cold season as a risk factor for morbidity and mortality from pneumonia [6] and other respiratory infections [16-18]. An underlying pathophysiological basis of an immunocompromised environment in the respiratory tract in cold weather has also been noted [19]. In children, for example, peripheral vasoconstriction decreases ciliary movement, thereby restricting the elimination of respiratory pathogens on the epithelium [20]. Meanwhile, vulnerable groups to pneumonia, such as children, have less ability to adjust to suddenly changing weather conditions [21], which may increase their risk. Nonetheless, further studies should focus on better explanations, including those based on immunological factors. Furthermore, future studies should address some unclear aspects of our findings, including our observation that cold weather, as represented as a low average temperature, was not precisely proportionate to increased risk, and our finding that the effect of pneumonia temperature was null in the elderly, who would be expected to be as vulnerable as children.

We found a protective effect of warm temperature in all ages and children, while the risk increased proportionate to both increasing and decreasing temperatures in the elderly. The latter finding for the elderly is similar to the typical Ushape pattern between average temperature and pneumonia that has been observed in many other studies $[6,22,23]$. However, studies have reported protective effects of lower or higher average temperatures [12], as was the case in our study for particular age subgroups. A possible explanation for this discrepancy may be the effects of cold and heat on humans. A proposed mechanism through which cold temperatures cause respiratory symptoms is that long-term exposure to cold air induces an inflammatory reaction in the lower respiratory tract [24]. However, although short-term exposure to cold air may increase the number of inflammatory cells, there is insufficient evidence to conclude that merely an increase in number is enough to trigger a pathological reaction [25]. Furthermore, studies relating temperature to health effects have often used somewhat extreme measures or endpoints such as heat waves, cold spells, or mortality, possibly due to issues involving reliability of the data [13]. However, these results should be reviewed carefully, since temperate climate areas rarely experience extreme weather, and ER visits are an issue distinct from mortality. From an etiological perspective, it could be argued that lower respiratory tract infections should be regarded differently [12] since they result from previous upper respiratory tract infections. Clearly, a more comprehensive understanding of host factors, personal susceptibility, and the possible predisposing role of different seasons, which may affect epidemics of pathogens like influenza or respiratory syncytial virus, is needed.

DTR was one of the variables that we evaluated to assess variance of temperature. It is different from pneumonia temperature in that the former variable indicates within-day variance. That is, while we can expect certain changes in health behavior in response to pneumonia weather (e.g., changes of clothing or refraining from outside activities), people have less chance to adjust to the DTR. As a result, and partly explained by pathophysiological mechanisms including inflammatory modifications and bronchospasm $[21,26]$, DTR has been observed to be closely related with the risk of respiratory diseases [27-30]. Furthermore, previous studies have commonly identified the elderly as the most vulnerable group, with effect estimates of around $1 \%$ change per $1{ }^{\circ} \mathrm{C}$ increase $[29,30]$, which is comparable to our result of a $0.8 \%$ change. However, no evidence seems to exist in the literature to support our results regarding all ages and children, both of which showed negative effects in response to the DTR. We assume that modifiers of the DTR not considered in our study may have affected our results [7], and that generated measures such as the DTR and pneumonia temperature are not as straightforward as direct measures, such as average temperature.

$\mathrm{RH}$ and WS were found to be of little significance in our study [17]. In tropical areas with abundant rainfall, humidity and precipitation are thought to be related to pneumonia [4]. However, in Korea, which has a temperate climate, more than half of the yearly precipitation is concentrated during 1-2 months in summer. With such a skewed distribution, patterns may arise that are different from those observed in other climate areas. Interestingly though, an increasing risk of pneumonia was observed in people aged over 65 years old when $\mathrm{RH}$ was extremely low. Considering that dry days are mostly in the late fall to winter, which overlaps with the seasonal influenza period, and influenza virus transmission is most efficient 
when the air is dry [31], low humidity may be considered a risk for pneumonia, particularly in older people.

Our study focused only on Seoul, which is a limitation for generalizing the results to the entire country. However, we expect that the overall meteorological conditions would be similar in other regions, since Korea has a relatively small geographical area. Nonetheless, sociodemographic factors may vary, and it is therefore necessary to consider other representative cities in further studies. The NEDIS data source also has some limitations. Its strengths are that the data are reported in real time and contain several clinical variables such as incidence date and body temperature, whereas claims data are usually reported monthly, and lack important variables for this study such as the incidence date. However, ER visits due to pneumonia may not be representative of all pneumonia cases. The ER is a first-response unit in hospitals where physicians can only report preliminary results or suspected diagnoses. Moreover, less severe cases may have been underrepresented in the data, because such patients are more likely to seek primary care or visit outpatient clinics, and more severe cases with many comorbidities may have also been underrepresented, since physicians may forget to add pneumonia as a diagnosis if the other symptoms are critical. It is quite difficult to completely avoid such misclassifications when using secondary data.

Despite its limitations, our study provided insights from 6 years of ER data in the capital of Korea. It is among the few studies that have used NEDIS data to relate various meteorological variables and to have investigated pneumonia in particular. Moreover, we evaluated the empirical term 'pneumonia weather' (or pneumonia temperature) from a public health standpoint and verified its validity. Further studies should expand the details of our findings by identifying risk groups and relationships with underlying medical conditions. It would also be meaningful to compare the patterns by different subtypes of pneumonia. In light of growing concerns about climate change, protective measures for pneumonia should carefully be prepared and tailored considering the different effects in specific age groups.

In conclusion, this study demonstrated the short-term effects of various meteorological variables on pneumonia. Pneumonia temperature, representing day-to-day variance in temperature, and the DTR, representing within-day variance, influenced ER visits due to pneumonia. Effects of average temperature and $\mathrm{RH}$ were also found. The magnitude of the effects varied across age groups and lag periods.

\section{CONFLICT OF INTEREST}

The authors have no conflicts of interest associated with the material presented in this paper.

\section{ACKNOWLEDGEMENTS}

This study was supported by a grant from the Transgovernmental Enterprise for Pandemic Influenza in Korea (TEPIK), which is a part of the Korea Healthcare Technology R\&D Project by the Ministry of Health and Welfare, Republic of Korea (grant No.: A103001).

\section{ORCID}

Sangho Sohn http://orcid.org/0000-0003-2736-3461

Jin A Kim http://orcid.org/0000-0002-5323-739X

Alaa Altaluoni $\quad h t t p: / / o r c i d . o r g / 0000-0003-2761-5091$

Kwan Hong http://orcid.org/0000-0002-5083-8026

Byung Chul Chun http://orcid.org/0000-0001-6576-8916

\section{REFERENCES}

1. Statistics Korea. Causes of death statistics in 2016 [cited 2018 Aug 31]. Available from: http://kostat.go.kr/portal/korea/kor_ nw/3/index.board?bmode $=$ download\&bSeq $=$ \&aSeq $=3632$ 69\&ord $=5$ (Korean)

2. Braga AL, Zanobetti A, Schwartz J. The effect of weather on respiratory and cardiovascular deaths in 12 U.S. cities. Environ Health Perspect 2002;110(9):859-863.

3. Chung JY, Honda Y, Hong YC, Pan XC, Guo YL, Kim H. Ambient temperature and mortality: an international study in four capital cities of East Asia. Sci Total Environ 2009;408(2):390-396.

4. Kim J, Kim JH, Cheong HK, Kim H, Honda Y, Ha M, et al. Effect of climate factors on the childhood pneumonia in Papua New Guinea: a time-series analysis Int J Environ Res Public Health 2016;13(2):213.

5. Liu L, Breitner S, Pan X, Franck U, Leitte AM, Wiedensohler A, et al. Associations between air temperature and cardio-respiratory mortality in the urban area of Beijing, China: a time-series analysis. Environ Health 2011;10:51.

6. Liu Y, Kan H, Xu J, Rogers D, Peng L, Ye X, et al. Temporal relationship between hospital admissions for pneumonia and weather conditions in Shanghai, China: a time-series analysis. BMJ Open 2014;4(7):e004961. 
7. Lim YH, Park AK, Kim H. Modifiers of diurnal temperature range and mortality association in six Korean cities. Int J Biometeorol 2012;56(1):33-42.

8. Kan H, London SJ, Chen H, Song G, Chen G, Jiang L, et al. Diurnal temperature range and daily mortality in Shanghai, China. Environ Res 2007;103(3):424-431.

9. Lim YH, Hong YC, Kim H. Effects of diurnal temperature range on cardiovascular and respiratory hospital admissions in Korea. Sci Total Environ 2012;417-418:55-60.

10. Nascimento-Carvalho CM, Cardoso MR, Barral A, Araújo-Neto CA, Oliveira JR, Sobral LS, et al. Seasonal patterns of viral and bacterial infections among children hospitalized with community-acquired pneumonia in a tropical region. Scand J Infect Dis 2010;42(11-12):839-844.

11. Chan PW, Chew FT, Tan TN, Chua KB, Hooi PS. Seasonal variation in respiratory syncytial virus chest infection in the tropics. Pediatr Pulmonol 2002;34(1):47-51.

12. Mäkinen TM, Juvonen R, Jokelainen J, Harju TH, Peitso A, Bloigu $A$, et al. Cold temperature and low humidity are associated with increased occurrence of respiratory tract infections. Respir Med 2009;103(3):456-462.

13. Basu R, Samet JM. Relation between elevated ambient temperature and mortality: a review of the epidemiologic evidence. Epidemiol Rev 2002;24(2):190-202.

14. Paynter S, Ware RS, Weinstein P, Williams G, Sly PD. Childhood pneumonia: a neglected, climate-sensitive disease? Lancet 2010;376(9755):1804-1805.

15. Lessler J, Reich NG, Brookmeyer R, Perl TM, Nelson KE, Cummings DA. Incubation periods of acute respiratory viral infections: a systematic review. Lancet Infect Dis 2009;9(5):291-300.

16. Donaldson GC, Goldring JJ, Wedzicha JA. Influence of season on exacerbation characteristics in patients with COPD. Chest 2012;141(1):94-100.

17. Falagas ME, Theocharis $G$, Spanos A, Vlara LA, Issaris EA, Panos $\mathrm{G}$, et al. Effect of meteorological variables on the incidence of respiratory tract infections. Respir Med 2008;102(5):733-737.

18. Murdoch DR, Jennings LC. Association of respiratory virus activity and environmental factors with the incidence of invasive pneumococcal disease. J Infect 2009;58(1):37-46.

19. Eccles R, Wilkinson JE. Exposure to cold and acute upper respiratory tract infection. Rhinology 2015;53(2):99-106.

20. Tian DD, Jiang $\mathrm{R}$, Chen XJ, Ye Q. Meteorological factors on the incidence of MP and RSV pneumonia in children. PLoS One 2017;12(3):e0173409.

21. Xu Z, Etzel RA, Su H, Huang C, Guo Y, Tong S. Impact of ambient temperature on children's health: a systematic review. Environ Res 2012;117:120-131.

22. Green RS, Basu R, Malig B, Broadwin R, Kim JJ, Ostro B. The effect of temperature on hospital admissions in nine California counties. Int J Public Health 2010;55(2):113-121.

23. Shiri R, Solovieva S, Husgafvel-Pursiainen K, Taimela S, Saarikoski LA, Huupponen $\mathrm{R}$, et al. The association between obesity and the prevalence of low back pain in young adults: the Cardiovascular Risk in Young Finns Study. Am J Epidemiol 2008; 167(9):1110-1119.

24. Larsson $\mathrm{K}$, Ohlsén P, Larsson L, Malmberg P, Rydström PO, UIriksen $\mathrm{H}$. High prevalence of asthma in cross country skiers. BMJ 1993;307(6915):1326-1329.

25. Larsson K, Tornling G, Gavhed D, Müller-Suur C, Palmberg L. Inhalation of cold air increases the number of inflammatory cells in the lungs in healthy subjects. Eur Respir J 1998;12(4): $825-830$

26. Graudenz GS, Landgraf RG, Jancar S, Tribess A, Fonseca SG, Faé KC, et al. The role of allergic rhinitis in nasal responses to sudden temperature changes. J Allergy Clin Immunol 2006; 118(5):1126-1132.

27. Ge WZ, Xu F, Zhao ZH, Zhao JZ, Kan HD. Association between diurnal temperature range and respiratory tract infections. Biomed Environ Sci 2013;26(3):222-225.

28. Xu Z, Huang C, Su H, Turner LR, Qiao Z, Tong S. Diurnal temperature range and childhood asthma: a time-series study. Environ Health 2013;12:12.

29. Wang MZ, Zheng S, He SL, Li B, Teng HJ, Wang SG, et al. The association between diurnal temperature range and emergency room admissions for cardiovascular, respiratory, digestive and genitourinary disease among the elderly: a time series study. Sci Total Environ 2013;456-457:370-375.

30. Li T, Yang Z, Wang M. Diurnal temperature range may be the risk factor for respiratory tract infections among the elderly in Guangzhou, China. Int J Biometeorol 2014;58(3):309-310.

31. Lowen AC, Mubareka S, Steel J, Palese P. Influenza virus transmission is dependent on relative humidity and temperature. PLoS Pathog 2007;3(10):1470-1476. 